\title{
Train of Ability of Chemistry Teachers to make of higher order thinking skills Learning Indicators
}

\author{
Ismono \\ Jurusan kimia FMIPA Unesa \\ Email. ismono@unesa.ac.id
}

\begin{abstract}
Based on the 2013 Curriculum (K-13), the ability to think at a higher level is an ability that must be possessed by every teacher, especially chemistry teachers. This study aims to determine the ability of teachers in compiling indicators of achievement of learning outcomes that require high order thinking skills. This research was conducted on Chemistry teachers who took part in professional education activities of teachers in positions ranging from batch 1 to 4, in 2019. There were 40 teachers who were subject of research in Chemistry. The results obtained are based on the results of testing about $2 \%$ of teachers who have been able to compile indicators of learning outcomes based on semi-high thinking (C3). Teachers after attending training above $97 \%$ are able to compile indicators of learning outcomes based on higher order thinking (C4). The increase in n-gains increases with a high category
\end{abstract}

Keywords: higher order thinking skill,

\section{A. Pendahuluan}

Tantangan para Guru atau calon guru IPA (kimia) di abad 21 yaitu guru atau calon guru harus (a) mampu melibatkan para peserta didik untuk secara aktif mengikuti proses pembelajaran seperti dalam berdiskusi, curah pendapat (brainstroming), bekerja dan belajar secara kolaboratif; (b) mampu meningkatkan kemampuan berpikir tingkat tinggi dan hasil belajar peserta didik secara optimal $[1,2,3,4,5]$.

IPA merupakan ilmu yang berbasis inkuiri dan mengedepankan logika berpikir tingkat tinggi, kemampuan generalisasi dan abstraksi yang cukup tinggi untuk memahami konsep kimia. Para guru IPA (kimia) saat ini masih banyak guru yang belum baik dalam memahami kompetensi dasar minimal yang harus dicapai oleh peserta didik dan urutan serta keterkaitan antar konsep-konsep, sehingga berdampak pada cara menyampaikan kerunutan dan keterkaitan antar konsep materi ajar [6].

Dampak lain pada peserta didik antara lain (1) Peserta didik mengalami kesulitan dan miskonsepsi dalam mempelajari konsepkonsep materi kimia yang kaya akan konsepkonsep abstrak, kemungkinan disebabkan guru kurang melatihkan peserta didik dalam menganalisis keterkaitan konsep-konsep dalam materi kimia $[7,8]$.

Adlaon (2012) menyatakan bahwa materi ajar yang kaya dengan konsep-konsep abstrak dan antar konsep-konsep memiliki keterkaitan, relatif sulit, untuk mengajarkan ke para peserta didik maupun cara peserta didik mempelajarinya, karena materi ajar tersebut. Pola pembelajaran pada materi yang berkonsep abstrak banyak diberikan dalam bentuk menghafal informasi (konsep), sehingga peserta didik menjadi pasif yang berakibat para peserta didik gagal dalam membangun konsep yang kuat dan kerangka kerja proposisional [9]. Barbara, (2005), peserta didik dalam memahami materi reaksi pada kimia organik banyak mengalami kesulitan bahkan tidak mampu dalam menghubungkan keterkaitan konsep dalam kimia organik karena peserta didik hanya menghafal bagaimana menulis tatanama dan hasil reaksi kimia organik [10].

Harris (2016) guru-guru SMA umumnya hanya mampu menyusun soal yang mengukur kemampuan berpikir tingkat rendah (lower order thinking skilss) [6].

Vol. 4, No. 1, June 2020 (43-50) 
Berdasarkan hasil penelitian dari beberapa pakar di atas, maka para guru sebelum mengajarkan materi ajar kepada peserta didik, sebaiknya: (a) menganalisis tuntutan kemampuan minimal peserta didik yang diharapkan dalam kompetensi dasar ; (b) konsep-konsep esensial dan keterkaitan antar konsep yang akan diajarkan; dan (c) cara membelajarkannya agar peserta didik mampu mengembangkan potensinya secara maksimal $[1,3,6]$.

Kompetensi inti dan kompetensi dasar dalam kurikulum 2013 (K-13) pada mata pelajaran (mapel) sebagian besar menuntut .kemampuan berpikir tingkat tinggi, baik di kelas X, XI, dan XII, KI-3 seperti;

Memahami, menerapkan, menganalisis pengetahuan faktual, konseptual, prosedural berdasarkan rasa ingintahu tentang ...menerapkan pengetahuan prosedural pada bidang kajian yang spesifik sesuai dengan bakat dan minatnya untuk menyelesaikan masalah... [1].

Berdasarkan tuntutan kurikulu K-13, maka bila dilakukan kajian maka KD yang berbasis berpikir tingkat tinggi (menganalisis) pada kelas X, XI, dan XII disajikan pada Tabel 1, 2, dan 3 [1].

Tabel 1 Contoh KD berpikir menganalisis di Kelas X

\begin{tabular}{cl}
\hline $\begin{array}{c}\text { No } \\
\text { KD }\end{array}$ & \multicolumn{1}{c}{ Kompetensi Dasar } \\
\hline 3.2 & $\begin{array}{l}\text { Menganalisis perkembangan model atom dari } \\
\text { model atom Dalton, Thomson, Rutherford, } \\
\text { Bohr, dan Mekanika Gelombang.. }\end{array}$ \\
\hline 3.4 & $\begin{array}{l}\text { Menganalisis kemiripan sifat unsur dalam } \\
\text { golongan dan keperiodikannya. }\end{array}$ \\
\hline 3.8 & $\begin{array}{l}\text { Menganalisis sifat larutan berdasarkan daya } \\
\text { hantar listriknya. }\end{array}$ \\
\hline
\end{tabular}

Tabel 2 Contoh KD berpikir menganalisis di Kelas XI

\begin{tabular}{cl}
\hline $\begin{array}{c}\text { No } \\
\text { KD }\end{array}$ & \multicolumn{1}{c}{ Kompetensi Dasar } \\
\hline 3.1 & $\begin{array}{l}\text { Menganalisis struktur dan sifat senyawa } \\
\text { hidrokarbon berdasarkan kekhasan atom } \\
\text { karbon dan golongan senyawanya. }\end{array}$ \\
\hline 3.9 & $\begin{array}{l}\text { Menganalisis faktor-faktor yang } \\
\text { mempengaruhi pergeseran arah } \\
\text { kesetimbangan dan penerapannya dalam } \\
\text { industri. }\end{array}$ \\
\hline 3.11 & $\begin{array}{l}\text { Menganalisis kesetimbangan ion dalam } \\
\text { larutan garam dan menghubungkan } p \text { H-nya. }\end{array}$ \\
\hline 3.13 & $\begin{array}{l}\text { Menganalisis data hasil berbagai jenis titrasi } \\
\text { asam-basa. }\end{array}$ \\
\hline
\end{tabular}

Tabel 3 Contoh KD berpikir menganalisis di Kelas XII

\begin{tabular}{cc}
\hline No & Kompetensi Dasar \\
KD & \\
\hline 3.1 & Menganalisis fenomena sifat koligatif larutan \\
\hline
\end{tabular}

\begin{tabular}{cl}
\hline $\begin{array}{c}\text { No } \\
\text { KD }\end{array}$ & \multicolumn{1}{c}{ Kompetensi Dasar } \\
& $\begin{array}{l}\text { (penurunan tekanan uap jenuh, kenaikan titik } \\
\text { didih, penurunan titik beku, dan tekanan } \\
\text { osmosis). }\end{array}$ \\
\hline 3.4 & $\begin{array}{l}\text { Menganalisis proses yang terjadi dalam sel } \\
\text { Volta dan menjelaskan kegunaannya. }\end{array}$ \\
\hline 3.5 & $\begin{array}{l}\text { Menganalisis faktor-faktor yang } \\
\text { mempengaruhi terjadinya korosi dan cara } \\
\text { mengatasinya. }\end{array}$ \\
\hline 3.7 & $\begin{array}{l}\text { Menganalisis kelimpahan, kecenderungan } \\
\text { sifat fisika dan kimia, manfaat, dan proses } \\
\text { pembuatan unsur-unsur golongan utama (gas } \\
\text { mulia, halogen, alkali, dan alkali tanah). }\end{array}$ \\
\hline 3.8 & $\begin{array}{l}\text { Menganalisis kelimpahan, kecenderungan } \\
\text { sifat fisika dan kimia, manfaat, dan proses } \\
\text { pembuatan unsur-unsur periode 3 dan } \\
\text { golongan transisi (periode 4). }\end{array}$ \\
\hline 3.9 & $\begin{array}{l}\text { Menganalisis struktur, tatanama, sifat, } \\
\text { sintesis, dan kegunaan senyawa Karbon }\end{array}$ \\
\hline 3.10 & $\begin{array}{l}\text { Menganalisis struktur, tata nama, sifat,dan } \\
\text { kegunaan benzena dan turunannya }\end{array}$ \\
\hline 3.11 & $\begin{array}{l}\text { Menganalisis struktur, tata nama, sifat dan } \\
\text { penggolongan makromolekul }\end{array}$ \\
\hline
\end{tabular}

Berdasarkan Tabel 1, 2, dan 3 terlihat kemampuan dasar menganalisis merupakan kemampuan yang harus dimiliki peserta didik, namun demikian kemampuan dasar menganalisis lebih dominan pada kelas XII. Kemampuan menganalisis di kelas XII (lebih dominan) karena kemampuan ini sangat diperlukan bagi peserta didik yang akan melanjutkan ke jenjang pendidikan yang lebih tinggi.

Pola pembelajaran pada materi yang berkonsep abstrak (kimia) (bagian dari IPA) banyak diberikan dalam bentuk menghafal informasi (konsep), sehingga peserta didik menjadi pasif yang berakibat para peserta didik gagal dalam membangun konsep yang kuat dan kerangka kerja proposisional [10].

Peserta didik dalam memahami materi reaksi pada kimia organik banyak mengalami kesulitan bahkan tidak mampu dalam menganalisis keterkaitan konsep dalam kimia (seperti kimia organik) karena peserta didik dalam mempelajari kimia hanya menghafal bagaimana menulis tatanama dan hasil reaksi [10.11,12].

Berdasarkan pendapat di atas, maka materi ajar yang kaya akan konsep yang abstrak, konsep-konsep terorganisir secara sistematis dan logis, di mana konsep-konsep tersebut 
tersusun secara hirarkis dan antar konsep kadangkala memiliki keterkaitan, sehingga untuk mempelajarinya diperlukan kemampuan berpikir tingkat tinggi.

Proses pembelajaran harus mampu menumbuhkan kemampuan peserta didik dalam menganalisis, mengevalusi, dan mensintesis agar peserta didik dapat memahami dan membangun konsep secara baik.

Berdasarkan hal di atas, maka penelitian ini akan mengkaji tentang "bagaimana kemampuan guru-guru kimia dalam menyusun indikator hasil belajar berbasis kemampuan berpikir tingkat tinggi,

B. Teori

Munzenmaier \& Rubin (2013), Berpikir tingkat tinggi terjadi ketika seseorang mengambil informasi yang tersimpan dalam memori dan menerima informasi baru yang saling berhubungan dan/ atau menata kembali danmemperluas informasi ini untuk mencapai suatu tujuan atau menemukan jawaban dari suatu permasalahan yang sulit. Berbagai tujuan dapat dicapai melalui pemikiran tingkat tinggi, seperti menganalisis, memprediksi, mensintesis, memutuskan apa yang harus dilakukan dan diputuskan (mengevaluasi), mensintesis ide baru atau objek baru (mensintesis/create). danmemecahkan masalah [13].

Anderson \& Krathwohl, (2001) menyatakan bahwa, kemampuan berpikir tinggi dapat dimulai dari menganalisis (analyze, C4), mengevaluasi (evaluate, C5) dan membuat (create) atau mensintesis (C6). Pengetahuan dan pemahaman yang sering disebut sebagai keterampilan berpikir tingkat rendah. Keterampilan berpikir aplikasi (C3) dikatagorikan dalam semi berpikir tingkat tinggi (semi higher order thinking skills) [14].

King et al. (2012), berpendapat bahwa kemampuan berpikir tingkat tinggi meliputi kemampuan untuk menganalisis, mensintesis, mengevaluasi proses dan produk, dan menghasilkan produk. Aplikasi dari kemampuan berpikir tingkat tinggi yaitu menghasilkan penjelasan detail, keputusan dan produk yang berlaku dalam konteks pengetahuan dan pengalaman yang tersedia dan yang mempromosikan pertumbuhan berkelanjut an dan keterampilan intelektual lainnya. Kemampuan berpikir tingkat tinggi perlu dilatihkan, ditumbuh dan kembangkan pada kognitif peserta didik agar peserta didik memiliki kemampuan untuk memecahkan masalah, memahami konsep abstrak dengan baik dan menciptakan atau membangun ide-ide baru [15].

Strategi pengajaran yang tepat untuk meningkatkan kemampuan keterampilan berpikir tinggi yaitu memfasilitasi lingkungan belajar yang mampu kondusif dan menantang peserta didik seperti kolaboratif, inkuri, diskusi, brainstroming, dan advanced organizer $[16,17,18]$.

Kegiatan dalam kelompok kecil seperti diskusi mahasiswa, tutor teman sebaya, dan pembelajaran kooperatif dapat efektif dalam pengembangan keterampilan berpikir. Kegiatan harus melibatkan tugastugas yang menantang, dorongan guru untuk tetap pada tugas, dan umpan balik yang sedang berlangsung tentang kemajuan kelompok. Hal ini dapat efektif dalam membangun keterampilan dalam bidang-bidang seperti analogi verbal, berpikir logis, dan induktif/penalaran deduktif [15].

Lewis dan Smith (1993). Berpikir tingkat tinggi terjadi ketika seseorang mengambil informasi baru dan informasi yang tersimpan dalam memori dan hubungan intern (interrelates) dan/atau menata kembali, membuat keterkaitan informasi dalam bentuk jaringan dan meluaskan informasi ini untuk mencapai tujuan atau menemukan kemungkinan jawaban dalam situasi membingungkan [19].

Berbagai tujuan dapat dicapai melalui pemikiran yang lebih tinggi, misalkan Vol. 4, No. 1, June 2020 (43-50) 
..memutuskan apa yang harus diyakini kebenaran ilmiahnya; memutuskan apa yang harus dilakukan; menciptakan ide baru, objek baru, atau ekspresi hasil karya; membuat prediksi; dan menyelesaikan masalah yang tidak rutin [20].

Gagne et al, (1988) berpendapat bahwa keterampilan berpikir tingkat tinggi senantiasa mengacu pada generalisasiyang menggambarkan hubungan antara atau di antara konsep-konsep sebagai"aturan" [21].

Keterampilan berpikir tingkat tinggi meliputi menganalisis, mengevaluasi, dan mensintesis, memerlukan penguasaan tingkat sebelumnya seperti pengetahuan, pemahaman dan aplikasi. Berpikir tingkat tinggi juga melibatkan bahan kompleks untuk diuraikan menjadi bagian-bagian yang sederhana, mendeteksi hubungan, dan menggabungkan informasi baru [22].

Piaget, menyatakan bahwa pesera didik yang menginjak remaja pindah ke masa dewasa (Usia di atas 15 tahun), mereka mampumengembangkan keterampilan seperti penggunaan logis dari simbolsimbol yang berkaitan dengan konsepkonsep abstrak, penalaran ilmiah, danpengujianhipotesis. Keterampilan inimerupakan dasar untuk pemecahan masalah, refleksi diri, dan penalaran tinggi dan kritis [23].

Berdasarkan kajian dari beberapa pendapat para pakar di atas dapat dinyatakan bahwa kemampuan berpikir tinggi merupakan kemampuan berpikir yang sangat dibutuhkan di era saat ini dan dapat diajarkan oleh para peserta didik yang memiliki usia di atas 11 tahun.

\section{Metode penelitian}

Penelitian ini merupakan penelitian deskriptif Analisis disktiptifnya meliputi analisis $\%$ peningkatan para guru kimia yang dapat menyusun indikator capaian hasil belajar berbasis kemampuan berpikir tingkat tinggi sebelum dan sesudah pelatihan. Analisis juga menggunakan analisis kenaikan n-gains [25].

Rambu-rambu penilaian penyusunan indicator capaian hasil belajar yang digunakan dapat dilihat pada Tabel 4.

Tabel 4 Rambu-rambu penilaian Indikator Capaian Hasi Belajar dengan KD Menganalisis

\begin{tabular}{ll}
\hline Indikator Capaian Hasil Belajar & skor \\
\hline Mengukur pengetahuan(C1) & 1 \\
\hline Mengukur pemaham (C2) & 2 \\
\hline Mengukur penerapan (C3) & 3 \\
\hline Mengukur menganalisis (C4) & 4 \\
\hline Mengukur mengevaluasi (C5) & 5 \\
\hline Mengukur mensintesis (C6) & 6 \\
\hline
\end{tabular}

Ket: Skor 1 s.d 6 dianalogikan dengan kemampuan kognitif taksonomi Bloom

\section{Hasil dan Pembahasan}

Berdasarkan hasil tes awal tentang pengetahuan para guru, ternyata para guru peserta PPG dalam jabatan belum mampu menyusun indikator capaian hasil belajar seperti yang diharapkan dalam KD K-13, secara detail dapat dilihat pada Tabel 5 di (Lampiran 1, 2, dan 3).

Berdasarkan Tabel 5 (Lampiran 1) KD Analisis di kelas $\mathrm{X}$, tampak bahwa sebanyak $97,9 \%$ guru menuliskan indicator ketercapaian hasil belajar pada kemampuan C2 dan 2,1\% di kemampuan C1. Kedua kemampuan tersebut merupakan kemampuan berpikir tingkat rendah (lower order thinking skills).

Tabel 6 (Lampiran 2) merupakan data hasil dari guru dalam menyusun indicator ketercapaian hasil belajar pada KD Analisis, di kelas XI.

Berdasarkan Tabel 6 terlihat bahwa kemampuan guru dalam menyusun indicator ketercapaian hasil belajar pada kemampuan C2 sebesar $80 \%$, sedangkan pada kemampuan $\mathrm{C} 3$ (semi berpikir tingkat tinggi) sebesar $20 \%$.

Tabel 7 (Lampiran 3) merupakan data hasil dari guru dalam menyusun indicator 
ketercapaian hasil belajar pada KD Analisis, di kelas XII.

Berdasarkan data pada Tabel 7, bahwa ada sekitar 2,27\% guru yang menuliskan indicator capaian hasil belajar hanya mengukur kemampuan $\mathrm{C} 1$, dan 97,73\% mengukur kemampuan $\mathrm{C} 2$.

Berdasarkan data dari Tabel 5, 6, dan 7 tampak bahwa sebagai besar guru $100 \%$ di kelas X, $80 \%$ di kelas XI, dan $100 \%$ di kelas XII, yang menuliskan indicator ketercapai hasil belajar pada kemampuan $\mathrm{C} 1$ dan $\mathrm{C} 2$. Indikator ketercapaian yang ditulis oleh para guru belum sesuai dengan $\mathrm{KD}$ yang diharapkan pada $\mathrm{K} 13$, yaitu kemampuan dasar menganalisis (C4) berdasarkan taksonomi Bloom. Kemampuan menganlisis merupakan kemampuan berpikir tingkat tinggi.

Berdasarkan hasil uji awal di atas, maka dilakukan pelatihan dan masukkan kepada para guru untuk mencermati secara teliti setiap KD yang terdapat dalam K 13, seperti harapan Permendikbud nomer 37, tahun 2018.

Para guru diawal proses pelatihan diberikan wawasan dalam mencermati tutuntan setiap KD baik kelas X s.d. XII pada K13 untuk mata pelajaran kimia. Para guru kemudian melakukan diskusi dengan curah pendapat dalam mencermati setiap KD.

Para guru secara berkelompok menyusun indicator capaian hasil belajar seperti yang diharapkan pada setiap KD, khususnya KD yang menuntut kemampuan menganalisis. Hasil dari pelatihan terjadi perubahan kemampuan guru dalam menuliskan indikayor capaian hasil belajar yang menuntut kompetensi menganalisis. Data hasilnya seperti yang disajikan pada Tabel 8.

Tabel 8 Kemampuan Rata-rata Guru dalam Menyusun Indikator Ketercapaian Hasil Belajar dengan KD Menganalisis.

\begin{tabular}{lllll}
\hline Kelas & No KD & $\begin{array}{l}\text { Jml } \\
\text { guru }\end{array}$ & C4 & $\begin{array}{l}\text { Jml } \\
\text { skor }\end{array}$ \\
\hline $\mathrm{X}$ & 3.2 & 40 & 4 & 160 \\
\hline
\end{tabular}

\begin{tabular}{lllll}
\hline Kelas & No KD & $\begin{array}{l}\text { Jml } \\
\text { guru }\end{array}$ & C4 & $\begin{array}{l}\text { Jml } \\
\text { skor }\end{array}$ \\
\hline & 3.4 & 40 & 4 & 160 \\
\cline { 2 - 5 } & 3.8 & 40 & 4 & 160 \\
\hline \multicolumn{2}{l}{ Total skor } & & & 480 \\
\hline XI & 3.1 & 40 & 4 & 160 \\
\cline { 2 - 5 } & 3.9 & 40 & 4 & 160 \\
\cline { 2 - 5 } & 3.11 & 38 & 4 & 152 \\
\cline { 2 - 5 } & 3.13 & 37 & 4 & 148 \\
\hline \multicolumn{2}{l}{ Total skor } & & & 620 \\
\hline XII & 3.1 & 40 & 4 & 160 \\
\cline { 2 - 5 } & 3.4 & 40 & 4 & 160 \\
\cline { 2 - 5 } & 3.5 & 40 & 4 & 160 \\
\cline { 2 - 5 } & 3.8 & 36 & 4 & 144 \\
\cline { 2 - 5 } & 3.9 & 35 & 4 & 140 \\
\cline { 2 - 5 } & 3.10 & 38 & 4 & 152 \\
\cline { 2 - 5 } & 3.11 & 40 & 4 & 160 \\
\hline \multicolumn{2}{l}{ Total skor }
\end{tabular}

Kenaikan skor rata-rata kemampuan para guru dalam menyusun indicator hasil belajar dengan KD menganalis untuk setiap KD setelah pelatihan relatif sangat tinggi, seperti yang disajikan pada Gambar 1, 2, dan 3 untuk setiap kelas X, XI, dan XII.

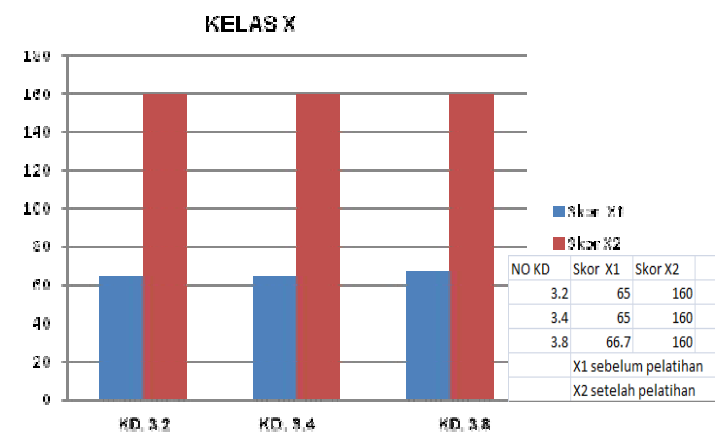

Gambar 1 Grafik Kenaikan KD Analisis kelas X

Berdasarkan Gambar 1 terlihat bahwa setelah para guru menjalani pelatihan, mengalami kenaikan kemampuan para guru dalam menyusun indicator capaian hasil belajar berdasarkan KD Menganalisis mapel kimia di kelas $X$ dari rata skor 65 menjadi skor 160 .

Kasus ini juga terjadi di kelas XI, di mana kemampuan para guru dalam menyusun indicator capaian hasil belajar berbasis KD menganalisis setelah menjalani pelatihan menjadi peningkatan skor yait dari rata-rata skor 80 menjadi 155 , sperti yang terlihat pada Gambar 2 . 


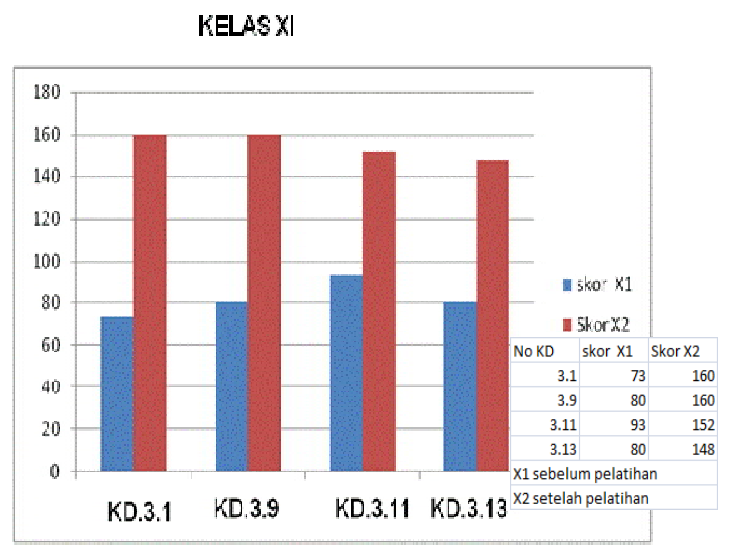

Gambar 2 Grafik Kenaikan KD Analisis kelas XI

Kasus yang sama juga terjadi pada kelas XII, di mana kemampuan guru dalammenyusun indicator capaian hasil belajar berbasis KD menganalisis juga mengalami kenaikan yang signifikan, seperti yang disajikan pada Gambar 3.

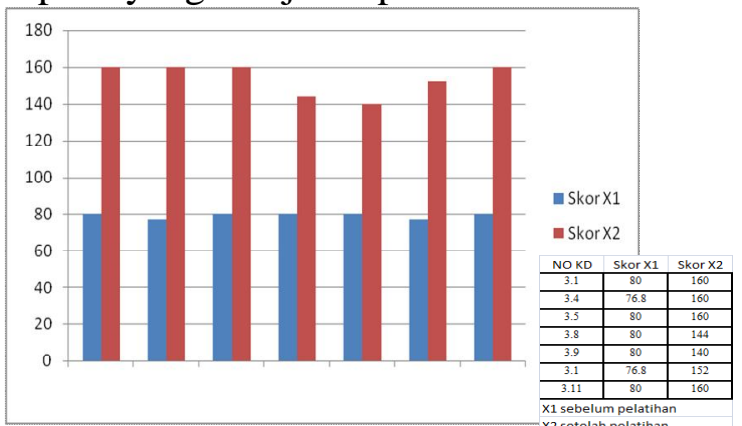

Gambar 3 Grafik Kenaikan KD Analisis kelas XII

Kenaikan skor n-gains pada setiap indicator capaian hasil belajar untuk setiap KD Menganalisis di setiap jenjang kelas di sajikan pada Tabel 9.

\begin{tabular}{lcccrc}
\multicolumn{7}{c}{ Tabel 9} & Kenaikan n-gains \\
\multirow{2}{*}{ Kelas } & No. & Skor & Skor & n-gains & katagori \\
& KD & X1 & X2 & & \\
\hline \multirow{3}{*}{ X } & 3.2 & 65 & 160 & 1 & tinggi \\
\cline { 2 - 7 } & 3.4 & 65 & 160 & 1 & tinggi \\
\cline { 2 - 7 } & 3.8 & 66.7 & 160 & 1 & tinggi \\
\cline { 2 - 7 } & 3.1 & $\mathbf{7 3}$ & $\mathbf{1 6 0}$ & 1 & tinggi \\
\hline XI & 3.1 & $\mathbf{7 3}$ & $\mathbf{1 6 0}$ & 1 & tinggi \\
\cline { 2 - 7 } & 3.9 & $\mathbf{8 0}$ & $\mathbf{1 6 0}$ & 1 & tinggi \\
\cline { 2 - 7 } & 3.11 & $\mathbf{9 3}$ & $\mathbf{1 5 2}$ & 0,88 & tinggi \\
\cline { 2 - 7 } & 3.13 & $\mathbf{8 0}$ & $\mathbf{1 4 8}$ & 0,85 & tinggi \\
\hline & 3.1 & 80 & 160 & 1 & tinggi \\
\hline XII & 3.4 & 76.8 & 160 & 1 & tinggi \\
\hline & 3.5 & 80 & 160 & 1 & tinggi \\
\hline & 3.8 & 80 & 144 & 0,8 & tinggi \\
\hline
\end{tabular}

\begin{tabular}{rcccrl}
\hline Kelas & $\begin{array}{l}\text { No. } \\
\text { KD }\end{array}$ & $\begin{array}{l}\text { Skor } \\
\text { X1 }\end{array}$ & $\begin{array}{l}\text { Skor } \\
\text { X2 }\end{array}$ & n-gains & katagori \\
\hline 3.9 & 80 & 140 & 0,75 & tinggi \\
\hline & 3.1 & 76.8 & 152 & 0,915 & tinggi \\
\hline 3.11 & 80 & 160 & 1 & tinggi \\
\hline
\end{tabular}

Berdasarkan Tabel 9, terlihat bahwa kemampuan para guru dalam menyusun indicator ketercapaian hasil belajar berbasis KD menganalsisis, setelah pelatihan mengalami kenaikan n-gains dengan katagori tinggi.

Berdasarkan hasil wawancara dan angket, para guru setelah pelatihan mulai memahami makna yang dipesankan dalam $\mathrm{KD}$ di $\mathrm{K}$ 13, khususnya KD yang menuntut kemampuan berpikir tingkat tinggi, seperti menganalisis.

\section{Simpulan dan Saran}

1. Simpulan

a. Para guru kimia peserta PPG, sebelum pelatihan hanya mampu menyusun indicator capaian hasil belajar pada kemampuan berpikir tingkat rendah $\mathrm{C} 2$.

b. Para guru peserta PPG setelah pelatihan mampu menyusun indicator capaian hasil belajar pada kemampuan berpikir tingkat tinggi $\mathrm{C} 4$.

c. Kenaikan n-gains para guru dalam menyusun indicator capaian hasil belajar meningkat dengan katagori tinggi

2. Saran

a. Pelatihankepada para guru untuk menyusun indicator capaian hasil belajar berbasis kemampuan berpikir tingkat tigi perlu terus dilakukan, karena hal tersebut akan berdampak pada cara membelajarkan dan penyusunan instrument tes yang menuntut kemampuan berpikir tingkat tinggi

b. Para guru sebaiknya melanjutkan mengembangkannya dalam RPP, pelakanaan pembelajaran sesuai

Vol. 4, No. 1, June 2020 (43-50) 
dengan KD menganalisis, dan penyusunan instrument tes.

\section{Daftar Pustaka}

[1] Permendikbud RI No. 37. 2018 . Perubahan atas Peraturan Menteri Pendidikan dan Kebudayaan Nomor 24 tahun 2016, tentang Kompetensi Inti dan Kompetensi Dasar Pelajaran pada Kurikulum 2013pada Pendidikan Dasar dan Menengah. Jakarta.

[2] NRC. 2001. Inquiry and the National Science Education Standards. A Guide for Teaching and Learning, National Academy Press, Washington, DC. http://books.nap.edu/html/inquiry_addendu $\mathrm{m} /$ (2 of 2) [9/10/2001 3:37:45 PM] akses juli 2015.

[3] Sudrajad, Ahmad. 2013. Tantangan Guru Dalam Dunia Pendidikan dan Gambaran Pendidikan dalam Abad 21, http://akhmadsudrajat.wordpress.com/2013/ 07/02/ paradigma-pendidikan-indonesiaabad-ke-2. Akses Mei 2014

[4] Hammann, Lynne A. 2012. How To Promote Higher-Order Thinking In The Classroom: Reflecting And Writing, Not Reciting And Reacting (with Reflection Questions). http://www.unco.edu/cetl/ sir/stating_outcome/documents/Krathwohl. pdf. akses. 2015.

[5] Widana I Wayan. 2017. Modul Higher Order Thinking Skills (HOTS). Direktorat Pembinaan SMA Direktorat Jenderal Pendidikan Dasar dan Menengah. Departemen Pendidikan dan Kebudayan. Jakarta.

[6] Harris Iskandar. 2015. Penyusunan Soal Higher Order Thinking Skills. Direktorat Jenderal Pendidikan Dasar dan Menengah. Departemen Pendidikan dan Kebudayan. Jakarta.

[7] Sarquis, A. M.; Taylor, B. A. P. 1991, Improving Physical Science Instruction in Elementary Classrooms; School. Science Curriculum Conference; Co-Directors; American Chemical Society: Washington, $\mathrm{DC}$,

[8] Gabel Dorothy. 1999. Improving Teaching and Learning through Chemistry
Education Research: A Look to the Future. Journal of Chemical Education 76 (4), 548553.

[9] Adlaon, R. B. 2012. Assessing effectiveness of concept map as instructional tool in high school Biology. (Unpublished Master's dissertation in Natural Sciences), Louisiana State University and Agricultural and Mechanical College, Baton Rouge, Louisians.

[10] Barbara Šketa., \& Saša Aleksij Glažarb. 2005. Using Concept Maps in Teaching Organic Chemical Reactions. J. Acta Chim. Slov. 2005, 52, 471-477.

[11] Ismono. 2015. Penggunaan Pembelajaran Berbasis Peta Konsep dalam Meningkatkan Proses dan Hasil Belajar Mahasiswa Pendidikan Kimia FMIPA Unesa pada Materi Pokok Isomer, Prosiding Seminar Nasional Kimia. ISBN : 978-602-0951-00-8, 3 Oktober 2015.

[12] Ismono., Sri Poedjiatoeti., Suyatno. 2016. Pengembangan model pembelajaran peta konsep berbasis inkuiri untuk melatihkan berpikir tingkat tinggi mahasiswa pendidikan kimia pada materi pokok isomer. Proseding seminar pendidikan IPA UM Malang. Vol 1. 2016. ISBN. 978602-9286-21-2. pasca.um.ac.id/wpcontent/uploads/2017/02/Ismono-639651.pdf.

[13] Munzenmaier, C., and Rubin, N. 2013. Perpectives, Bloom's Taxonomy: What's Old is New Again. Learning Guild Research.

http://educationalelearningresources.yolas ite.com/ resources/guidresearchbloom $2013 \%$ 1320(1).pdf. Akses Oktober 2014.

[14] Anderson, L. W. \& Krathwohl, D. R. 2001. A taxonomy for learning, teaching and assessing: A revision of Bloom's taxonomy of educational objectives. New York: Longman.

[15] King F.J., Ludwika G., \& Faranak R., 2012. Higher Order Thinking Skills. Educational Service Program Publisher.

[16] Klingner, J., Vaughn, S., Dimino, J., Schumm, J., \& Bryant, D. 2001. From 
clunk to click: Collaborative Strategic Reading. Longmont, CO: Sopris West.

[17] Slavin, R. E. 2008. Cooperative learning, success for all, and evidence-based reform in education. In É ducation et didactique, vol 2/2008, 149-157.

[18] Slavin, R. E. 2010. Co-operative learning: what makes group work? In H. Dumont, Istance, \& F. Benavides (Eds.), The Nature of Learning: Using Research to Inspire Practice (pp. 161-178). Paris: OECD.

[19] Lewis, A., \& Smith, D. 1993. Defining higher order thinking. Theory into Practice, 32 (3), 131-137.

[20] Limbach, B., \& Waugh, W. 2010. Developing Higher Level Thinking. Journal of Instructional Pedagogies. p: $1-9$.

[21] Gagne, R.; Briggs, L.; Wager, W. 1988. Principles of Instructional Design. $4^{\text {th }}$ Edition. ISBN 0-03-034757-

2. https://www.scribd.com/document/323 442622/Gagne-R-Briggs-L-Wager-W-

Principles-of-Instructional-Design. Akses Oktober 2015.

[22] McDavitt, David S. 1994. Teaching for Understanding: Attaining Higher Order Learning and Increased Achievement through Experiential Instruction. Non journal. ERIC Number: ED374093.

[23] Piaget, J. $1994 . \quad$ Cognitive Development in children: Piaget Development and Learning, J.Res. in Sci. Teaching, 1964, 2:176-186.

[24] Hake, R.R. 1998. Interactiveengagement vs traditional methods: A six-thousand-student survey of mechanics test data for introductory physics courses. Am. J. Phys. 66(1):64-74; also at < http://www.physics.indiana.edu/ sdi. 